\title{
Designing a Mobile Augmented Memory System for People with Traumatic Brain Injuries
}

\author{
Carole Chang, Annika Hinze, Judy Bowen and Nicola Starkey \\ University of Waikato, New Zealand \\ Email: sc200@students.waikato.ac.nz, hinze@waikato.ac.nz, jbowen@waikato.ac.nz,nstarkey@waikato.ac.nz
}

\begin{abstract}
Augmented memory systems help people remember events in their lives. Individuals with Traumatic Brain Injury (TBI) often have memory impairments. We conducted a user study to learn about strategies individuals with TBI use to remember events in their lives. We explored what characteristics individuals with TBI expect of an augmented memory system. We then investigated these aspects in an initial mobile app design, and propose here a concept for a rehearsal application that addresses the issues found in our studies.
\end{abstract}

\section{INTRODUCTION}

Traumatic Brain Injury (TBI) is a leading cause of death and disability in young adults throughout the world [1], with male adolescents (15-25 year olds) being the highest risk group [2]. The most common causes of TBI are motor vehicle accidents and interpersonal violence. TBI is considered a 'silent epidemic' in NZ because it is under-reported, not well diagnosed and poorly managed. $70-90 \%$ of individuals with TBI have a 'mild' injury, with $40-80 \%$ of them suffering post-concussive symptoms, such as physical, cognitive, and behavioural difficulties. Medicines and therapy can reduce the physical or behavioural difficulties but not the cognitive issues. "Memory dysfunction" is a common symptom, and most people with TBI have difficulties concentrating, problems with calculations, list-generating, and memory [3]. 54\% of people with moderate TBI are not able to return to their previous life/work due to memory dysfunction [4]. Autobiographical memory refers to an individual's history and the memories of their learning and experiences [5]. People might forget some of these memories over time but recollection can often be triggered by exposure to cues. After TBI, storage and retrieval are more difficult; the memory impairments take many forms depending on the nature of the injury [6]. They include relatively minor memory slips and lapses, such as those everyone experiences from time to time (e.g., forgetting the name of a familiar person), to more severe problems, such as anterograde amnesia - the inability to form new memories [7]. Our project focusses on the development of an augmented memory system to help people with TBI.

Existing computer science research into augmenting memory focusses largely on using digital records aimed at capturing everything a person does and sees via videos or photos. Even though 'capturing everything' is a major focus of existing systems, its benefits for memory and remembering are poorly explored. However, this concept is often used in systems for people with Alzheimer's disease (AD) [8]. Sellen and Whittaker [9] argue that an effective system should rather focus on using contextual information as cues to trigger memory instead of trying to record the memories themselves. Our project builds on one such system, the Digital Parrot, an augmented memory system that uses cues instead of a captureall approach [10]. This paper has two main contributions:

1. Identifying coping strategies \& requirements. Currently, there is a lack of detailed information about which aspects of memory loss are most problematic for individuals with TBI in their daily lives and what coping strategies they have developed. We conducted a user study to learn how to best support the memory functions of TBI. Together with the participants, we compiled a list of requirements for an augmented memory system.

2. Initial mobile app design and interface concept. We explored options to easily capture memories in an initial study with non-TBI people. The insights from our TBI user study and this smaller study shaped our prototype design for a rehearsal app for individuals with TBI.

\section{RELATED WORK}

We discuss here the most closely related approaches and argue why they do not provide solutions for people with TBI.

Systems for Alzheimer's Disease (AD) Alzheimer's disease is a progressive irreversible brain disease that impacts on daily living through memory loss and cognitive changes [11]. There are some similarities in memory symptoms to those of individuals with TBI but they have different causes and different long-term effects. Existing electronic aids for $\mathrm{AD}$ are of two main types: locating support and memory support. Locating support systems use GPS or multi-modal sensors to track AD patients who lose orientation, or have difficulty remembering direction [12], [13]. They cannot solve the cognitive problems of people with TBI experience but may provide additional help if needed. Most memory support systems use life-logging technology to record personal experiences, and present these recordings to AD patients to help with their day to day tasks [8], [14]. These life-logging technologies capture amounts and complexity of data that are overwhelming for people with TBI. We therefore conclude that the solutions for Alzheimer's patients are not solutions for people with TBI.

ExpiryDate [15] This iPhone application was created by an individual to support a relative with anterograde amnesia due to a brain tumour. It helps users by providing reminders for expiry dates of every-day items (e.g., food). The interface uses time-bricks to display information, which includes pictures of, or icons for, items, and their expiry date or remaining time, ordered by expiry date. Although ExpiryDate is a custom-made memory system for individuals with memory problems, ]its functions are not sufficient to support people with TBI, as memories of every-day events may not necessarily have an 
expiry date. What is required is a memory system that not only provides reminders of events to come but also functions as a memory assistant. Rehearsal is an essential factor when aiming to remember and ExpiryDate does not support this aspect.

Digital Parrot This augmented memory system uses cue information (such as time, location, people, weather) to create a memory network [16]. Retrieving stored data is guided via a graph view and four navigation tools: type navigator, timeline navigator, map navigator and textual search. The interface provides rich options to explore the cue network, which have been shown to be successful in supporting memory retrieval [16]. However, many people with TBI report difficulties with desktop-based systems as their use often leads to headaches. Furthermore, stationary systems are problematic for active people [7]. Even though the mobile version of the Digital Parrot [17] overcomes some of the shortcomings of the Digital Parrot, it still is not a solution for individuals with TBI (too much data and too many options).

\section{INTERVIEW STUDY}

We conducted a user study to explore memory impairments post-TBI, with the goal to (1) investigate aspects of memory impairment that affected people and/or their caregivers/supporters find the most distressing and disruptive, (2) explore strategies they and their caregivers currently use, and (3) identify requirements for memory aids.

\section{A. Procedure}

Recruiting of participants focussed predominantly on individuals with TBI and their caregivers. We used semi-structured interviews that captured information about the participants and their situation pre-injury and post-injury, their occupational situation, living arrangements, memory aids they use, and experience of using computers and smart phones. We also asked about the participants' experiences with memory aids. Participants were asked to describe what techniques they use to remember things in different situations, such as doctor's appointments or family events. We investigated participants' experience with using electronic devices to assist their memories. This last part used open questions that aimed at collecting the participants' opinion about the memory aids they need.

\section{B. Participants}

We interviewed 21 to date: 17 participants with TBI, and five caregivers/supporters, and one with Multiple sclerosis (MS). We acknowledge that MS is degenerative and the experiences are not necessarily the same as with TBI. However, we hope that our research might be of benefit for people with other types of memory problems. A summary of the data is provided in Fig. 1. We found that brain injury caused other symptoms including major depressive disorder, headaches, visual and hearing problems and personality change, many of which lead to participants having to significantly change their lives. For example, a hearing problem meant P1 had to to give up being a police officer. P3 could not be a pilot because of the diagnosed potential epilepsy. Emotional problems are another symptom (e.g., P4 experiences severe frustration when she is under pressure). Hearing and visual problems cause P5 social isolation and low self esteem. P6 was the only participant with a moderate injury; he lost all of his semantic and episodic memories. Through rehabilitation and physical recovery, he slowly and continuously retrieved the semantic memory back. His episodic memory is triggered by associated items, e.g., smelling curry could trigger his memory of travel in India. Repeated head injury in the early childhood of P13 caused attention deficit disorder (ADD), which means she cannot concentrate on forming new memories, while her Post-traumatic stress disorder (PTSD) means she may recall unwanted memories. Therefore, she needs to consciously organise the tasks in her life avoiding relying on routine. P20 reported that she grows fatigued from trying to remember ordinary things (e.g., after cooking one time she forgot to turn off the oven and it was still on in the morning). Caregivers and supporters were found to usually assist with remembering people or social activities. All of the TBI participants in this study have the ability to live largely independently.

\section{Discussion}

1) Five Factors of Memory: We identified five factors location, activity, people, emotion and time - which affect the memory of individuals with TBI. We found that information about location and about familiar people (42\%) are equally important for triggering memories. We note that location seems to have a greater influence for individuals with TBI than for those without [18]. All participants reported difficulties in remembering people's names and faces and for unfamiliar people, 12 of 21 participants stated that location is most important to trigger their memory. All participants agreed that activity $(33 \%)$ is the second factor. Emotions and environmental (25\%) were named as another factor: they are usually associated with big events and not so much with everyday memories. We now discuss the findings for each factor.

a) Location and People: Information about people is too complex and varied for people with TBI. It often includes names and faces, and sometimes related information such as the person's size, their hair style, or clothes. This is too much to process as their short-term memory is easily disturbed while trying to transfer the information into long-term memory. Also, some factors could change such as hair colour or style. All participants reported they required their full concentration when they commit something to memory. As people in social occasions often do more than one thing concurrently, such as having a conversation during dinner time, this poses great challenges for people with TBI. P1 admitted he could not remember any personal information when people introduce themselves during an activity. P2 and P19 (caregivers) also reported how $\mathrm{P} 1$ and $\mathrm{P} 18$, respectively, found it hard to remember peoples' names and faces. Many others (e.g., P4, P5, P7 and P8) found they had the same problem when they interacted with people. P12 and P15 told us that they cannot recognise their tutor's face after one semester teaching. P14, P16, P17, P18 and P20 described how they lost their social ability post-TBI with the main reason being that they cannot retain new information about people, their conversations and activities. In contrast, locations consist of simpler information such as a name or address, which is much easier for TBI patients to remember. All participants reported that they could remember a location or landmark they had visited and used them to trigger their memories. P2 described how location was the first cue used when she supported P1 retrieving his 


\begin{tabular}{|c|c|c|c|c|c|c|c|c|c|c|}
\hline & $\mathrm{M} / \mathrm{F}$ & \begin{tabular}{|c|} 
Age \\
accident \\
/now
\end{tabular} & TBI Level & Cause & Other Symptoms & $\begin{array}{c}\text { Recove- } \\
\text { ry(in } \\
\text { weeks) }\end{array} \mid$ & Current Job & $\begin{array}{l}\text { Memory } \\
\text { Problems }\end{array}$ & Particular Problems & Coping Strategies \\
\hline P1 & M & $20 / 34$ & mild & $\begin{array}{l}\text { motor vehicle } \\
\text { accident }\end{array}$ & $\begin{array}{l}\text { Major depressive disorder, } \\
\text { Migraine, Left hearing loss }\end{array}$ & 52 & $\begin{array}{c}\text { Secondary } \\
\text { School Teacher } \\
\text { (F) }\end{array}$ & $\begin{array}{l}\text { short-term } \\
\text { memory }\end{array}$ & \begin{tabular}{|c|} 
remembering new \\
acquaintances, plans for daily \\
life
\end{tabular} & uses $\mathrm{P} 2$ as personal reminder \\
\hline P2 & $\mathrm{F}$ & $/ 32$ & \begin{tabular}{|c|} 
support P1 \\
(wife)
\end{tabular} & & & & & & $\begin{array}{c}\text { wants record of plans that have } \\
\text { been made }\end{array}$ & reminds $P 1$ via SMS + verbal \\
\hline P3 & M & $15 / 21$ & mild & $\begin{array}{c}\text { cerebral tumor } \\
\text { excised }\end{array}$ & $\begin{array}{l}\text { Narrow vision (20 deg), Double } \\
\text { vision, Balance problems }\end{array}$ & 3 & \begin{tabular}{|c|}
$\begin{array}{c}\text { Tertiary Student } \\
\text { (F) }\end{array}$ \\
\end{tabular} & \begin{tabular}{|c|} 
short-term \\
memory (esp. \\
sociall) \\
\end{tabular} & plans for daily life & none/ SMS from friends \\
\hline P4 & $\mathrm{F}$ & $15 / 23$ & mild & child abuse & $\begin{array}{l}\text { Generalized anxiety disorder, } \\
\text { Migraine }\end{array}$ & 6 & $\begin{array}{c}\text { Tertiary Student } \\
\text { (F) }\end{array}$ & $\begin{array}{c}\text { short-term } \\
\text { memory }\end{array}$ & aggravated unders stress & flash cards white board \\
\hline P5 & M & $20 / 38$ & mild & $\begin{array}{c}\text { industrial } \\
\text { accident ('96), } \\
\text { motor vehicle } \\
\text { accident (' } 08)\end{array}$ & $\begin{array}{l}\text { Major depressive disorder, } \\
\text { Hearing problems, Visual } \\
\text { problems, Balance problems }\end{array}$ & 2 & $\begin{array}{c}\text { Manager of Tyre } \\
\text { Company (F) }\end{array}$ & $\begin{array}{c}\text { short+long- } \\
\text { term memory }\end{array}$ & $\begin{array}{l}\text { remembering new } \\
\text { acquaintances, remembering } \\
\text { conversations, no social life }\end{array}$ & $\begin{array}{l}\text { type everything +print out } \\
\text { (unreadable handwriting) }\end{array}$ \\
\hline P6 & M & $25 / 32$ & moderate & sporting accident & Visual problems & 52 & \begin{tabular}{|l|} 
Tertiary Student \\
(F) \& Painter (P) \\
\end{tabular} & $\begin{array}{c}\text { short-term } \\
\text { memory }\end{array}$ & plans for the day & write down schedule for next day \\
\hline P7 & $\mathrm{F}$ & $32 / 49$ & mild & $\begin{array}{l}\text { motor vehicle } \\
\text { accident }\end{array}$ & $\begin{array}{c}\text { Migraine, Personality change, } \\
\text { Visual problems }\end{array}$ & 4 & \begin{tabular}{|c|} 
Newspaper \\
Delivery (F) \& \\
single mum \\
\end{tabular} & $\begin{array}{c}\text { short+long- } \\
\text { term memory }\end{array}$ & remembering ways & $\begin{array}{l}\text { practice ways (to work, to a meeting } \\
\text { etc) + friends phone }\end{array}$ \\
\hline P8 & $\mathrm{F}$ & $28 / 40$ & [MS] & $\begin{array}{c}\text { MS-caused brain } \\
\text { lesions }\end{array}$ & $\begin{array}{c}\text { Muscle spasms, Muscle } \\
\text { weakness }\end{array}$ & $\mathrm{n} / \mathrm{a}$ & \begin{tabular}{|l|} 
Tertiary Student \\
(P) \& single mum
\end{tabular} & $\begin{array}{c}\text { short-term } \\
\text { memory }\end{array}$ & $\begin{array}{c}\text { details and plans for daily life, } \\
\text { new information }\end{array}$ & $\begin{array}{l}\text { post-its, placement of items, SMS } \\
\text { from family }\end{array}$ \\
\hline P9 & M & $/ 18$ & \begin{tabular}{|c|}
$\begin{array}{c}\text { support P8 } \\
\text { (son) }\end{array}$ \\
\end{tabular} & & & & & & plans for daily life & SMS to P8, placing physical items \\
\hline P10 & M & $16 / 67$ & mild & bike accident & & 1 & retired & $\begin{array}{l}\text { short-term } \\
\text { memory }\end{array}$ & $\begin{array}{l}\text { remembering new } \\
\text { acquaintances, plans for daily } \\
\text { life }\end{array}$ & $\begin{array}{l}\text { writes electroncic diary + new plans } \\
\text { at end of the day }\end{array}$ \\
\hline P11 & $\mathrm{F}$ & $/ 34$ & \begin{tabular}{|c|} 
support \\
P10 \\
(daughter) \\
\end{tabular} & & about P10: mood swings & & & $\begin{array}{l}\text { aggravated } \\
\text { since } \\
\text { emotional }\end{array}$ & remembering social details & advance emails to P10 \\
\hline P12 & $\mathrm{F}$ & $15 / 22$ & mild & bike accident & Sensitive to light & 1 & \begin{tabular}{|c|} 
Tertiary Student \\
(F)
\end{tabular} & $\begin{array}{c}\text { short-term } \\
\text { memory }\end{array}$ & $\begin{array}{l}\text { plans for the day, details of } \\
\text { daily life }\end{array}$ & $\begin{array}{l}\text { schedule on paper/phone, small } \\
\text { paper drawings }\end{array}$ \\
\hline P13 & $\mathrm{F}$ & $\begin{array}{c}\text { child } / 4 \\
0\end{array}$ & mild & child abuse & PTSD, ADD & $?$ & $\begin{array}{l}\text { Tertiary Student } \\
\text { (P) \& single mum }\end{array}$ & $\begin{array}{l}\text { short-term } \\
\text { memory }\end{array}$ & plans for daily life & $\begin{array}{l}\text { strict following schedule, paper } \\
\text { calendar, colour-coding, electronic } \\
\text { scetching }\end{array}$ \\
\hline P14 & $\mathrm{F}$ & $13 / 41$ & mild & bike accident & blackouts, epilepsy, fatique & $?$ & office worker $(P)$ & $\begin{array}{c}\text { short-term } \\
\text { memory }\end{array}$ & plans for daily life & electronic notes on phone \\
\hline P15 & $\mathrm{F}$ & $16 / 23$ & mild & sporting accident & & 2 & \begin{tabular}{|c|} 
Tertiary Student \\
(F)
\end{tabular} & $\begin{array}{c}\text { short-term } \\
\text { memory }\end{array}$ & plans for the day & $\begin{array}{l}\text { paper diary, relying on mother as } \\
\text { support person (verbal reminders) }\end{array}$ \\
\hline P16 & $\mathrm{F}$ & $34 / 60$ & moderate & $\begin{array}{c}\text { motor vehicle } \\
\text { accident }\end{array}$ & \begin{tabular}{|c|}
$\begin{array}{c}\text { permanent disabilities, balance } \\
\text { problems }\end{array}$ \\
\end{tabular} & 52 & $\mathrm{n} / \mathrm{a}$ & $\begin{array}{c}\text { short-term } \\
\text { memory }\end{array}$ & & $\begin{array}{c}\text { labelled physical files with } \\
\text { information, calendar with names }\end{array}$ \\
\hline P17 & $\mathrm{F}$ & $58 / 59$ & mild & brain tumor & $\begin{array}{c}\text { fatigue, headaches, difficulty } \\
\text { concentrating, seizures, not } \\
\text { allowed to drive }\end{array}$ & 52 & retired & $\begin{array}{l}\text { short-term } \\
\text { memory }\end{array}$ & daily life & $\begin{array}{c}\text { paper-based todo list, shared } \\
\text { whiteboard with husband, relies on } \\
\text { reminders from husband }\end{array}$ \\
\hline P18 & M & $22 / 60$ & moderate & $\begin{array}{l}\text { motor vehicle } \\
\text { accident }\end{array}$ & $\begin{array}{c}\text { permanent disabilities, fatigue, } \\
\text { poor eye sight }\end{array}$ & 104 & n/a & $\begin{array}{l}\text { short+long- } \\
\text { term memory }\end{array}$ & $\begin{array}{l}\text { details of daily life, } \\
\text { acquaintances }\end{array}$ & $\begin{array}{c}\text { rely on SMS from friends, } \\
\text { (sometimes unreadable) paper } \\
\text { notes }\end{array}$ \\
\hline P19 & M & 34 & $\begin{array}{c}\text { support } \\
\text { P18 } \\
\text { (caregiver) }\end{array}$ & & & & & & \begin{tabular}{|c|} 
about P18: difficulty to \\
remember unfamiliar persons \\
or facts without strong context
\end{tabular} & $\begin{array}{l}\text { paper-based todo list, shared } \\
\text { whiteboard with husband, relies on } \\
\text { reminders from husband }\end{array}$ \\
\hline P20 & $\mathrm{F}$ & $44 / 51$ & mild & sporting accident & $\begin{array}{c}\text { fatigue, major depressive } \\
\text { disorder, poor eye sight }\end{array}$ & ? & $\mathrm{n} / \mathrm{a}$ & \begin{tabular}{|l|} 
short+long- \\
term memory
\end{tabular} & $\begin{array}{l}\text { details of daily life, no } \\
\text { multitasking (forgetting way) }\end{array}$ & none \\
\hline P21 & $\mathrm{F}$ & $56 / 62$ & moderate & $\begin{array}{c}\text { motor vehicle } \\
\text { accident }\end{array}$ & fatigue, flat speech & $?$ & Nurse (P) & $\begin{array}{c}\text { short-term } \\
\text { memory }\end{array}$ & plans for daily life & $\begin{array}{c}\text { keeps paper notes on bench, relies } \\
\text { on husband to remind }\end{array}$ \\
\hline
\end{tabular}

Fig. 1. Participant Information (P: part-time job of 20hrs/week. F: full-time job of $40 \mathrm{hrs} /$ week)

memories. P3 reported that location is the most effective cue for him. P7 usually used landmarks to trigger her memory. All 18 TBI participants reported that names or photos of locations are most effective for retrieving their memory.

b) Time: Time has different representations for individuals with TBI. For non-TBI people, time indicates a specific date or exact time frame (e.g. 1st of April or 5 pm on Friday). For people with TBI, time represents any portion of time of an event; such as "the afternoon we went to the supermarket" or "the morning of Dad's birthday". The participants reported that before considering the time of an event, they become aware of the event itself.

c) Activity: Activity was described as an effective cue to help retrieve memories. P2 reported that she often used previous activities to trigger P1's memory. For example, they met John at the wedding party and they talked about buying the house in Auckland. P1 could not remember John before P2 mentioned they had a conversation about buying the house in Auckland. If P2 mentioned they met John at the wedding party, P1 would remember that he met John, but without any personal information. We observed the same experience with all TBI participants. P4 described how she typically used a previous conversation to recall memories. P6 at first completely lost his memories after his brain injury; during rehabilitation he regained some of his memories. He told us that music, smell or photographs could bring him back to that time. P7 said: "familiar sounds or things can trigger my memories." P8 described activity as the main factor in their awareness of the present. Other caregiver participants (P9 and P11) also 
confirmed that activity is a factor they use to remind someone. Furthermore, P8, P13 and P21 emphasised that they remember an activity better if it had meaning for them. Therefore, we believe it to be beneficial to include explicit interactions into the interface of a memory aid as hooks to form a memory and aid later recall.

d) Emotion: This has been found to be an important an factor for triggering people's memory [5], [19] and this is also true for TBI patients. Each participant was able to tell us information about their accident, which included dates and details and we found that the participants who associated strong emotions with the accident (e.g., P1, P5 and P6) remembered most of their accident details, including the exact date and how and what happened during the accident. Moreover, P2 reported her observation that $\mathrm{P} 1$ could better remember those memories that involved strong emotions. However, we do not typically find strong emotions involved in everyday-memories and therefore emotion is the last of the factors we describe.

2) Memory Strategies: Individuals with TBI damaged different areas of their brain thus each has different requirements and most have developed their own strategies to assist their memory. In our study, we found that "keeping it fresh" is the major strategy for people with TBI. In cognitive psychology, this is referred to as repetition. People with TBI have shortterm memory deficits that impact on how they transfer information into long-term memory [20]. Rehearsal/repetition involves receiving (i.e., seeing/hearing) the information repeatedly to prevent it from vanishing from short-term memory. This way they can keep the information longer in short-term memory and thus improve its chances of transferring into long-term memory. TBI participants all agreed that post-it notes and fridgememos are good memory aids for retrieval. Most participants post information on the fridge door or kitchen bench to see it as often as possible. Post-it notes are popular because they are produced quickly and removed easily. In addition, P4, P13, P17, P19, and P21 place whiteboards in their room so they can review their schedule/notes. Several participants review the day every evening (in writing, e.g., P10, P13) and schedule their next day to refresh their memory of their plans (often including hand-written notes, drawings or reminders). These are other ways to implement rehearsal/repetition.

3) Technology Experience: All participants have experience in using smart phones. Four use both mobile phones (Samsung Galaxy SIII and iPhone 3G) and desktop systems (Windows 7 and Mac OS X). None of them use popular applications for assisting their memories, such as Google Calendar (online calendar) and Remember The Milk (online to-do list and task management). On the desktop computer, participants have their own favourite software to assist their memories. P5 uses sticky notes in Windows 7 to track tasks: notes stay on the desktop to remind him and once finished they are deleted. P3 uses software named Rainlendar instead of Google Calendar, because it uses colours to highlight different events, and events and tasks can be kept on the desktop. P4 uses a calendar on the Mac and also on the iPhone, which syncs between devices when updating events. P10 writes an electronic diary at the end of the day and includes plans for the future. P11 reported that P10 also uses email to help his memory because she may get over 10 mails from P10 per day. P9, P12, P14, P17, P18, P20 and P21 prefer to use SMS messages for memory cue storage, they keep these messages until they no longer need them (typically triple checking to confirm).

On mobile devices, most TBI participants use alarms to remind them of upcoming events. In addition, they all agree that the best display is a pop-up text reminder. However, they handle reminder situations differently: two participants set alarms without descriptions for daily activities such as taking medicine. They will only insert a description for unique events and then set more than one alarm. The number of alarms will increase for more important events. Another participant relies on his support person to remind him early in the day and also send SMS text messages or give a call 1-2 hours ahead of events. P6 was the only participant relying on a standard mobile phone with no calendar for reminders. He inputs the associated information of the appointment (that is the location, time and people) and then saves them into the notepad on the mobile. All information is categorised by date, followed by the time, and one record represents one event. For example, G12 Carole means "meeting with Carole at 12pm in G Block". 7 out of 18 TBI participants use the note application on their mobile devices but reported that sometimes the meaning of the notes are lost as they are not categorised (e.g., shopping).

\section{Suggestions for Memory Systems}

All participants were asked to describe their ideal application. From the discussions, we identified three features:

Simple: TBI participants want applications without too many functions as these are too complex for them. Therefore, they do not use popular applications already in the market. Ten participants stressed that they do not need 'fancy' software with 'frilly functions' because they do not have 'extra' memory space to learn how to use them. They prefer an application with a simple display and 'enough' functions. For example, a reminder requires just an alarm and a pop up message.

Discreet: They want the application to be socially acceptable so as to not cause embarrassment. This is a problem when remembering a person's information. For example, an application that can match the face and name from a phone contact when you take a picture of someone would be helpful but most likely not discreet enough to be acceptable.

Customisable: Each participant has their own approach to assist their memories and expects the software to support their strategies. People with TBI find it difficult to learn new strategies so keeping to known principles is best for them. For example, P4 usually uses visual reminders and hearing to assist recollection; she would like to have software which provides recording and replay of audio as a reminder.

Our user study confirms the results from a previous study related to effective ways of reminding TBI [21]. This study also shows that electronic devices may have the ability to increase the independence of individuals with TBI. The results from our user study highlight other issues the participants have in addition to memory problem, such as social issues [22]. We also have new findings of features that people with TBI require of the software, such as an application with a simple display and functionality. These requirements will be included in the prototype designs described in the next two sections. 


\section{Prototype Study of Capture Methods}

We developed a prototype for capturing and displaying memory cues with the aim of exploring some of the concepts that were suggested by our user study. Following the requirement of a customisable tool, we explored different types of media (photographs, audio recordings etc.) that people use to record their memories. We conducted an initial study to explore these options and used participants without TBI, so as to not burden our TBI participants with further studies at this early development stage.

\section{A. Setup and Participants}

We adapted the mobile version of the Digital Parrot to support different options of capturing memory cues (text notes and icon selection) and for finding memory cues (timeline and text/photo display). We aimed at using simpler interaction steps than the original Digital Parrot (e.g., simple large timeline icons instead of network or tabular view). We tested the interface with 12 participants (students between the ages of 20 and 25, 9 male, 3 female). We performed pre-study interviews regarding their preferences for memory tools, a mobile study, and post-study interviews to gain feedback on their experiences. Participants could use the mobile app in any way they wished during several scenarios that we conducted with them. The scenarios required them to remember information with the help of the app - in the library they needed to remember the details of a book they would later need to recall, and in several social situations they were required to remember details about a party invitation as well as the social occasion itself. These situations were designed to be similar to those we explored in our interviews (Section III).

\section{B. Discussion of observations}

We enquired about the participants' preferred methods of recording event information for later recall. We asked about five methods of capturing memory cues: pen \& paper, digital calendar, digital notes, photographs, and audio recordings for feedback (used frequently / occasionally /rarely or never). We additionally recorded methods that participants mentioned (one participant frequently uses geo-tagging and two use video recordings). Pen \& paper is used frequently by 5 , occasionally by 4 , and rarely or never by 3 of the 12 participants. Digital resources were reported to be used more often: calendar, notes and photography are used by 6 participants frequently, by 4 occasionally and by 2 rarely or never. We note that audio recordings were said to be rarely used by all 12 participants.

Our software offered the options of using digital notes, photographs, and audio recordings. Participants could decide which types of memory recordings they wished to make. 11 of the 12 participants took digital notes, all 12 participants took photographs, and nine of the participants recorded audio notes. In a second step, we then encouraged the participants to remember/find their notes with details for a particular memory. We also captured their feedback on the ease of use of the software and the effectiveness of the support for capturing and finding. All 12 participants felt they could capture with ease what they wanted ( 3 very easy, 6 easy, 3 neutral; 5 captured everything, and 7 captured most). Only seven found it easy (3) or very easy (4) to to find cues to recall a memory detail

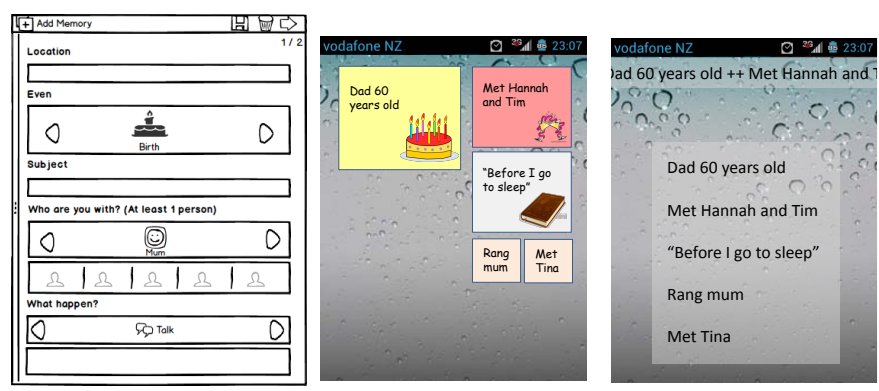

Fig. 2. Mock-ups of adding memories (step 1), post-it, screensaver

(additionally 4 neutral, 1 difficult), and 10 found everything they wanted, while 1 was neutral, and missed some items.

Finally, we enquired about how effective the participants thought each of these methods were for recalling memories. Not every participant had tried all three methods. However, all participants agreed (or strongly agreed) that the use of photographs was effective in aiding their memory, while ten participants felt the use of notes was effective and six out of the twelve felt that the use of audio was effective. It is interesting to observe that even though none of our participants would typically use audio notes, still more than half of them found them useful. We see this as promising for exploring audio recordings in addition to text and photos. Furthermore, we received positive feedback about our simplified timeline with icons which were reported to make it easy to quickly identify what each recorded event was about. However, participants also asked for more event types and icons to be available.

\section{REHEARSAL APPLICATION}

From our interview study and the prototype study, we concluded two fundamental points for our app for individuals with TBI. Firstly, the application should not be a reminder, but focus instead on the rehearsal of memories to be able to train the memory of people with TBI. Secondly, both visual and auditory rehearsal cues should be supported. We now describe our design of a memory app for people with TBI.

The app is initially being designed as an Android application which can run on a smartphone or tablet. The design of the capturing function follows the five factors of memory from the user study described in Section III-C. It includes location, event, related people, involved activities, date, time, mood and notes. Fig. 2 (left) shows step 1 of inputting the required information, the application also allows the user to complete the rest of the information later. This allows the user to insert just enough information for remembering without interrupting their social activity which meets the requirement of being discreet. All information use icons instead of text which meets the requirement of simplicity.

Visual representations produce a more vivid impression than text descriptions [5]. In the field of computer science, these are referred to as icons. In our interview study, all participants agree icons are more attractive than text descriptions. Furthermore, participants of the prototype study positively commented on the icons for identifying event types. We therefore require a big picture icon with text description 
to represent each item in our application which makes the interface simpler.

We designed four methods to implement rehearsal functions: Post-it, Screensaver, Flashcards and Recording. Postit and Screensaver are both visual prototypes. and rely on principles such as size and colour to differentiate categories and their importance. The principle of rehearsal/repetition means showing a task constantly until it has been committed to memory which both of these provide.

Post-it provides messages in various notes that look like physical post-it notes. It lists the five most important/urgent notes on the main screen and allows users to adjust their size and colour for emphasis. We set the display number to five notes as this is an acceptable number for a typical adult's memory span [23]. Users can change the post-it location according to their reading habits. Fig. 2 (middle) shows our post-it design on a mobile screen.

Screensaver uses a scrolling text displayed on the screensaver. The screensaver is typically the most active mode on a mobile device. We designed two different options: One shows scrolling text listing notes on the top region of the screen, the other shows three days' notes in the scrolling text within one text box (both are shown in Fig. 2, right).

Flash cards is a set of cards with information, such as numbers or words, often used in early childhood education. Teachers write one question on a card and an answer overleaf to be used as a learning drill based on spaced repetition. Our application will show flash cards which contain information about a memory with additional cues such as the subject and location to trigger the user's memory The application will then show the relevant information after a short time or the user can click the card to check the answer.

\section{CONCLUSION}

This project focuses on developing augmented memory systems for people with TBI. Even though previous studies of people with TBI have been undertaken, we needed to identify the specific requirements TBI people have for an augmented memory system. Data will have to be captured by, and presented to, mobile users such that an exploration of complex memories is supported without overwhelming the users. We have identified memory strategies and technology expectations of people with TBI. New findings from our study are the features that are required of a memory application, such as simple display and functionality. We explored the technical details in a prototype study and then implemented these findings into a prototype design. Our application is based on the principle of rehearsal. Rehearsal means showing information repeatedly until it has been committed to memory. Visual function includes using colour and size to emphasise categories and importance. We furthermore explore the idea of active rehearsal using digital flash cards. We currently have a horizontal prototype of the app which we are using for initial usability testing and are partway through developing the final app. For verification of our design model, we will involve people with and without brain injuries that are aged between 15 and 25 years. The solution sought in this project resides largely within computer science; however, the constraints and methodology for evaluation are strongly influenced by psychology and health-care considerations. We plan to therefore closely collaborate with local health-care providers in our future work.

\section{REFERENCES}

[1] S. Barker-Collo, N. Wilde, and V. Feigin, "Trends in head injury incidence in new zealand: A hospital-based study from 1997/1998 to 2003/2004," Neuroepidemiology, vol. 32, no. 1, pp. 32-39, 2009.

[2] V. L. Feigin et al., "Incidence of traumatic brain injury in new zealand: a population-based study," The Lancet Neurology, vol. 12, no. 1, pp. 53-64, 2012.

[3] T.-Y. Lee, "Assessing health-related quality of life," Master's thesis, Kaohsiung Medical University, Kaohsiung, Taiwan, 2004.

[4] C.-Y. Kuan, "Impact of cognition function in post-head injury patients or post-cingulotomy patients," Master's thesis, Kaohsiung Medical University, Kaohsiung, Taiwan, 2004.

[5] D. B. Willingham, Cognition: the thinking animal. New Jersey, USA: Prentice Hall, 2004.

[6] B. H. Dritschel, L. Kogan, A. Burton, E. Burton, and L. Goddard, "Everyday planning difficulties following traumatic brain injury: a role for autobiographical memory." Brain injury BI, vol. 12, no. 10, pp. 875-886, 1998.

[7] A. Hinze, C. Chang, and N. Starkey, "A psychology-based approach to augmented memory system for people with brain injury," in $3 r d$ International Workshop on Smart Healthcare Applications (part of OzCHI'11), 2011, pp. 29-31.

[8] M. Lee and A. Dey, "Providing good memory cues for people with episodic memory impairment," in ACM SIGACCESS conference on Computers and accessibility. ACM, 2007, pp. 131-138.

[9] A. J. Sellen and S. Whittaker, "Beyond total capture: a constructive critique of lifelogging," Commun. ACM, vol. 53, pp. 70-77, May 2010.

[10] A. Schweer, S. Jones, and A. Hinze, "Trails of experiences: navigating personal memories," in Proc. of the CHINZ.

[11] American Health Assistance Foundation, "Alzheimer's disease research," 2011.

[12] C. Giraldo, S. Helal, and W. Mann, "mPCA-A mobile patient caregiving assistant for Alzheimer patients," in First International Workshop on Ubiquitous Computing for Cognitive Aids (UbiCog'02), 2002.

[13] J. M. Zagami, S. A. Parl, J. J. Bussgang, and K. D. Melillo, "Providing universal location services using a wireless e911 location network," IEEE Communications Magazine, vol. 36, no. 4, pp. 66-71, 1998.

[14] M. Lee and A. Dey, "Lifelogging memory appliance for people with episodic memory impairment," in Conf. on Ubiquitous computing UbiComp '08. ACM, 2008, pp. 44-53.

[15] KCSOFT, "Expirydate, iphone app available online," http://itunes.apple.com/tw/app/expirydate/id522661649?mt=8, 2012, [Online; accessed 09-September-2012].

[16] A. Schweer, "Augmenting autobiographical memory: An approach based on cognitive psychology," Ph.D. dissertation, University of Waikato, Hamilton, New Zealand, 2011.

[17] J. Richmond, "Digital parrot on android," The University of Waikato, Hamilton, New Zealand, Report, 2012.

[18] J. Alallah, "Capturing situational context in an augmented memory system," Master's thesis, 2010.

[19] M. W. Eysenck and M. T. Keane, Cognitive Psychology: a student's handbook, 6th ed. New York, USA: Psychology Press, 2010.

[20] A. Baddeley, M. W. Eysenck, and M. Anderson, Memory. UK: Psychology Press, 2009.

[21] R. DePomper et al., "Practical applications for use of pdas and smartphones with childen and adolescents who have traumatic brain injury," NeuroRehabilition, vol. 23, no. 6, pp. 487-499, 2008.

[22] R. G. Knight and K. O'Hagan, "Autobiographical memory in longterm survivors of severe traumatic brain injury," Journal of Clinical and Experimental Neuropsychology, vol. 31, no. 5, pp. 575-583, 2009.

[23] M. H. Ashcraft, Fundamentals of cognition. New York, USA: Addison Wesley Educational publishers Inc., 1998. 